\title{
The Relations Between Phenylalanine-Ammonia Lyase, Glutathione-s-Transferase Activities and the Concentrations of Total Tannins, Phytochelatins, Glutathione, and Peroxidation in two Cultivars of Sorghum (Sorghum bicolor (L.) Moench) Exposed to Aluminum
}

\author{
Heidar Ali Malmir
}

Received: 17 December 2011/ Accepted: 20 May 2012/Published online: 5 September 2012

(C) The Author(s) 2012. This article is published with open access at Springerlink.com

\begin{abstract}
This article reports on the realtions between the activities of enzymes, such as phenylalanine-ammonia lyase (PAL) and glutathione-s-transferase (GST), and the concentrations of total tannins, total glutathione (TGSH), total phytochelatins (TPC), and lipid peroxidation (MDA) in leaves and roots of sorghum cultivars 132 and 552 that are exposed to four concentrations $\left(0,10,20\right.$, and $\left.30 \mathrm{mg} \mathrm{l}^{-1}\right)$ of $\mathrm{AlCl}_{3}$ in a mixture of river sand and peat. The $\mathrm{Al}^{3+}$ significantly increased the level of tannins, TGSH, and TPC in the roots and leaves of both cultivars. In the roots of both cultivars, the production of TPC was significantly coupled to decrease in the total TGSH. The concentration of TGSH in the leaves of cultivar 132 was found to be higher than in those of cultivar 552. In the plants treated with 10, 20, and $30 \mathrm{mg}^{-1} \mathrm{Al}^{3+}$, the PAL activities in leaves of both cultivars increased (by 73, 44, and $18 \%$, respectively), the TGSH in the roots of cultivar 552 declined (by 50, 45, and $23 \%$, respectively), the GST activities in the leaves of both cultivars were higher (90, 98, and $100 \%$, respectively) than those of the control plants. $\mathrm{Al}^{3+}$ also enhanced levels of MDA in the leaves and roots. These results suggested that the increase in PAL and GST activities might be controlled by antioxidant potentials and different routes of carbon channeling in the leaves. In cultivar 552, antioxidant compounds such as TPC and TGSH with rapid turnover and high accumulation were more effective than tannins for leaves because tannin was low. In cultivar 132, the amount of tannins was high and stable; therefore they do not need high accumulation of TPC in leaves. The depletion of TGSH can be ascribed to the $\mathrm{Al}^{3+}$-induced TPC synthesis in the leaves and roots of cultivar 552. The syntheses of TPC and MDA can be related to changes in TGSH and tannins, suggesting that TGSH and tannins are normally involved in $\mathrm{Al}^{3+}$ sequestration under conditions of subtoxic exposure. The increased TPC in the roots could provide an effective means of restricting $\mathrm{Al}^{3+}$ to these organs by chelating. In cultivar 552, TGSH contents may have been consumed for two strategies: the maintenance of regular redox potential, and the precursor for TPC.
\end{abstract}

Keywords Carbon channeling · GST $\cdot$ PAL activities · Tannin $\cdot$ Phytochelatins · Glutathione

\section{Introduction}

Most strategies of plant tolerance to $\mathrm{Al}^{3+}$ exposure are based on the reduction, by maintaining the cytosolic concentration of free $\mathrm{Al}^{3+}$. In this way, the plant cell avoids accumulation of $\mathrm{Al}^{3+}$ by compartmentalization, although this distribution is not clearly established yet [17]. Several

H. A. Malmir ( $\square)$

Department of Biology, University of Bu Ali Sina,

Hamedan, Iran

e-mail: malmir1@basu.ac.ir investigations described that $\mathrm{Al}^{3+}$ triggered increase in organic acid anion release from root tips of $\mathrm{Al}^{3+}$-tolerant plant [7]. Root exudation of phenolic compounds has been described by many authors. Phenolics can reverse the toxic effects of $\mathrm{Al}^{3+}$ on hexokinase [33]. However, at equimolar concentrations, they are less efficient than citrates in developing complexes with $\mathrm{Al}^{3+}$. Also, simple tannins like \{catechol\} are effective at low $\mathrm{pH}$, where $\mathrm{H}^{+}$efficiently competes with $\mathrm{Al}^{3+}$ for the binding sites in 1:1 complexes [2, 22]. Therefore, tannins' sites in themselves are considered important for complex formation with $\mathrm{Al}^{3+}$ in acidic environments. Recent investigations found 
$\mathrm{Al}^{3+}$-induced exudation of the flavonoid-type tannins \{catch in and quercetin from $10-\mathrm{mm}$ root tips in an $\mathrm{Al}^{3+}$-resistant maize variety $[2,6]$. The $\mathrm{Al}^{3+}$-induced exudation of \{catechin $\}$ at the rate of $100 \mu \mathrm{mol}$ per tip $\mathrm{h}^{-1}$ in comparison with citrate, which did not exceed $1 \eta \mathrm{mol}$ per tip $h^{-1}$, a rate reported for citrate exudation in maize by other authors [6].

The known proteins-SH compounds are small metalbinding peptides with the structure $(\gamma \text {-glu-cys })_{n}$-gly, in which " $n$ " varies from 2 to 11 . The synthesis from glutathione, homo-glutathione, hydroxymethyl-glutathione is catalyzed by a transpeptidase, and called phytochelatin (PC) synthesis [4], [30]. PC syntheses have been shown to be activated by a broad range of metals and metalloids, in particular $\mathrm{Cd}^{2+}, \mathrm{Ag}^{2+}, \mathrm{Zn}^{2+}, \mathrm{Cu}^{2+}$, and $\mathrm{Au}^{2+}$ [4].

In plants, total glutathione or TGSH (GSH + GSSG) is involved in cellular processes, including defense against reactive oxygen species (ROS). TGSH exists in two forms: reduced glutathione (GSH) and oxidized glutathione (GSSG). The reduction potential of glutathione depends on the intracellular GSH/GSSG ratio (Pekker et al. 2002). The conjugation of TGSH with such molecules is governed by glutathione $S$-transferase (GST). GST catalyzes the conjugation of TGSH with metal ions and helps them to sequester into vacuoles [16].

The control of oxidant levels is achieved by antioxidative systems. These defense systems are composed of metabolites, such as ascorbate, glutathione, tocopherol, tannin; and enzymatic scavengers of activated oxygen, such as superoxide dismutase, peroxidases, etc. [27].

Polyphenols are plant secondary metabolites consisting of condensed tannin, and are ${ }_{*} \mathrm{OH}$ radical scavengers because phenolic groups are excellent nucleophiles and are also able to quench lipid peroxidation, action as chain break antioxidant. Tannin chelates metal because of its ten galloyl groups, and it diminishes intestinal non-heme iron absorption [25].

In Sorghum's cultivars, tannin is an abundant component with as high as $8-15 \%$ of dry weight which prevents damage from $\mathrm{Al}^{3+}$ stress. In our previous chemical study, carried out on two cultivars, the results revealed that tannin in cultivar 132, was $10 \%$ higher than that in cultivar 552, although the leaves' toughness in cultivar 552 was higher than that in cultivar $132[19,22]$. Polyphenols compounds and specialized condensed tannins play an important role in plant defense by the oxidation of endogenous tannins compound into quinines [28]. PAL is considered the key enzyme in phenolic biosynthesis since it catalyzes the reductive deamination of $\mathrm{L}$-phenylalanine to form transcinnamic acid, the first step in the biosynthesis of plant phenylpropanoid compounds. Tolerance to $\mathrm{Al}^{3+}$ in sorghum may be defined as the ability to survive in a soil that is toxic to other plants. The question is whether this means that only a single biochemical or molecular change is required to produce tolerance to $\mathrm{Al}^{3+}$. The main goal of this study is to test the hypothesis by comparing the activities of TPC, TGSH, and tannins, in the detoxification of $\mathrm{Al}^{3+}$. We compared the GST activities of the two cultivars and tried to develop the relation between TGSH accumulation and $\mathrm{Al}^{3+}$-induced TPC synthesis, oxidative stress, and involvement of the key enzyme PAL in the first step of plant phenylpropanoid $i$ biosynthesis of in the leaves and roots of two cultivars of sorghum.

\section{Materials and Methods}

\section{Plant Materials}

The experiments were carried out between 21 April and 18 September 2010, under natural daylight in the University of $\mathrm{Bu}$ Ali Sian Hamadan. During growth season, the temperature ranged between $25 \pm 5^{\circ} \mathrm{C}$. In this study, two sorghum cultivars differing in $\mathrm{Al}^{3+}$ accumulation in leaves and roots were selected based on previous study [22]. The cultivars were obtained from the seed research center of Isfahan. The seeds were sterilized for $20 \mathrm{~min}$ in a $10 \%$ sodium hypochlorite solution. Seeds of two cultivars were cultivated in cycle pots with surface area of $1,015 \mathrm{~cm}^{2}$ and depth of $60 \mathrm{~cm}$.

The medium culture was river sand and peat in 3:1 ratio, respectively. The Hoagland's nutrient solution was added to each pot once in 2 weeks [15]. Simultaneously, the $\mathrm{AlCl}_{3}$ was applied in four concentrations $(0,10,20$, and $30 \mathrm{mg}^{-1}$ ) as thresholds fixed by (Juan et al. 2002). The plant samples were harvested 50 days after sowing.

\section{Sample Preparation}

After the incubation period, all seedlings were submerged in cold $10 \mathrm{mM} \mathrm{CaCl}_{2}$ for 10 min to remove the adhering $\mathrm{Al}^{3+}$ in roots surfaces. Then, they were washed with distilled water. The plant samples were cut into roots and leaves, and each part was homogenated and subdivided into two parts. One was immediately weighed and frozen in liquid nitrogen and kept at $-80{ }^{\circ} \mathrm{C}$ for analysis of total TPC, TGSH, tannin, and $\mathrm{Al}^{3+}$ concentrations. The fresh leaves and roots were sampled to determine GST, MDA, and PAL activities. Leaf areas per plant were determined (directed method) using a leaf area meter (LI 3100; Li-Cor, Lincoln, NB, USA). The samples were placed in the oven at $80{ }^{\circ} \mathrm{C}$ for 4 days; then the dry weight was measured separately.

\section{Determination of Total Phytochelatins (TPC)}

The TPC were extracted and assayed according to the method suggested previously [30]. In short, total TPC were 
extracted by homogenizing $0.5 \mathrm{~g}$ frozen plant material with $2 \mathrm{ml}$ of a $5 \%, 5$-sulfosalicyclic acid with $6.3 \mathrm{mM}$ diethylene triamine penta acetic (DTPA) at $0{ }^{\circ} \mathrm{C}$ (using mortar, pestle, and quartz sand). The homogenate was centrifuged at $12,000 \mathrm{~g}$ at $4{ }^{\circ} \mathrm{C}$ for $10 \mathrm{~min}$. Clear supernatants were collected and immediately used for the assay of total TPC compound. The concentrations of total TPC compound were determined using Ellmans reagent (DTNB). $300 \mu \mathrm{l}$ of supernatant was mixed with $630 \mu \mathrm{l}$ of $0.5 \mathrm{M} \mathrm{K}_{2} \mathrm{HPO}_{4}$, final $\mathrm{pH} 7.5$, and the absorbance was measured at $412 \mathrm{~nm}$ on a spectrophotometer (Perkin Elmer, Lambda 45, UV/vis D6484. USA). After addition of $25 \mu \mathrm{l}$ of DTNB solution (6.3 mM DTNB in $0.143 \mathrm{M} \mathrm{K}_{2} \mathrm{HPO}_{4}$ and $6.3 \mathrm{mM}$ DTPA, PH 7.5), the $\mathrm{A}_{412}$ was measured again after 2 min $\left(€_{\text {DTNB }}=13,600 \mathrm{~mol} \mathrm{l}^{-1} \mathrm{~min}^{-1} \mathrm{~cm}^{-1}\right)$.

Total PC $=($ Tot.vol. $/$ sample.vol $) \times$ OD412nm/13600 $=100 \times$ OD $412 \mathrm{~nm} / 13600$

\section{Determination of Total Glutathione (TGSH)}

The TGSH (GSH + GSSG) was extracted and assayed according to the method reported previously [9]. Frozen plant materials were homogenized in $0.1 \mathrm{M}$ sodium phosphate. 0.005 EDTA buffer (pH 8.0), and $25 \%$ metaphosphoric acid (used for protein precipitation). The glutathione cycles were continuously monitored between its oxidized and reduced forms; reduction of GSSG was being affected by NADPH and glutathione reductase, while non-enzymic oxidation of GSH was being affected by DTNB. The homogenate was centrifuged at $12,000 \mathrm{~g}$ at $4{ }^{\circ} \mathrm{C}$ for 15 min to obtain supernatant for TGSH determination. The ion of 5-carboxy-4-nitrothiophenol thus produced absorbs at $420 \mathrm{~nm}\left(€ 12.9 \times 10^{3} \mathrm{M}^{-1} \mathrm{~cm}^{-1}\right)$ and the reaction rate becomes linear (as a dynamic equilibrium between the two forms of glutathione is established) within $1 \mathrm{~min}$ and remains linear for $15 \mathrm{~min}$. Within a range of glutathione concentrations (70-350 nanomol-GSSG under the experimental conditions). The rate of increase of extinction at $350-420 \mathrm{~nm}$ is linearly related to the concentration of glutathione present. Total TGSH was determined fluorometrically and fluorescence intensity was recorded at $420 \mathrm{~nm}$ after excitation light at $350 \mathrm{~nm}$ on the Spectrophotometer. Linear regression analysis of the rates as a function of concentration at $420 \mathrm{~nm}$ after excitation at $350 \mathrm{~nm}$ was the following equation: Rate = $0.01464\left[\right.$ TGSH] $+0.0091, \mathrm{R}^{2}=0.997$.

Determination of Phenylalanine Ammonia-Lyase Activity (EC 4.3.1.5)

Activity of PAL was measured according to the method of [28], with slight modifications. To measure PAL, samples of $1 \mathrm{~g}$ of freshly weighed roots or leaves were ground in a chilled mortar in an ice bath with $0.5 \mathrm{~g}$ quartz sand, $0.5 \mathrm{~g}$ buffer saturated Polyclar AT, and $2 \mathrm{ml}$ of $0.1 \mathrm{~m}$ borate buffer ( $\mathrm{pH} 8.8$ ), 15/AM 2-mercaptoethanol. After centrifugation for $10 \mathrm{~min}$ at $20,000 \mathrm{~g}$, the supernatant was layered on a Sephadex G-25 column buffered with $0.1 \mathrm{~m}$ borate buffer ( $\mathrm{pH} 8.8$ ) and centrifuged. $1 \mathrm{ml}$ of enzyme extract was incubated with $2 \mathrm{ml}$ of borate buffer $(50 \mathrm{mM}$, $\mathrm{pH}=8.8)$ and $1 \mathrm{ml}$ of $\mathrm{L}$-phenylalanine $(20 \mathrm{mM})$ for $60 \mathrm{~min}$ at $37^{\circ} \mathrm{C}$. The reaction was stopped with $1 \mathrm{ml}$ of $1 \mathrm{M} \mathrm{HCl}$. The assay mixture was extracted with $3 \mathrm{ml}$ of toluene by overtaxing for $30 \mathrm{~s}$. The absorbance of toluene phase containing trans-cinnamic acid was measured at $290 \mathrm{~nm}$. Enzyme activity was expressed as $\eta$ mol transcinnamic acid released, $\mathrm{h}^{-1} \mathrm{~g}^{-1} \mathrm{FW}$.

Glutathione-s-Transferase (GST; EC 2.5.1.18)

The GST activity was determined spectrophotometrically according to the method of [8]. One gram of plant samples was extracted in $5 \mathrm{ml}$ medium containing $50 \mathrm{mM}$ phosphate buffer, pH 7.5, $1 \mathrm{mM}$ EDTA, and $1 \mathrm{mM}$ DTT. The enzyme activity was assayed in a reaction mixture containing $50 \mathrm{mM}$ phosphate buffer, $\mathrm{pH} 7.5,1 \mathrm{mM}$ 1-chloro2, 4-dinitrobenzene (CDNB). The reaction was initiated by the addition of $1 \mathrm{mM}$ TGSH, and formation of S-(2, 4-di nitrophenyl) glutathione (DNP-GS) was monitored for increase in absorbance at $340 \mathrm{~nm}$ to calculate the GSTspecific activity.

\section{Determination of Tannins Compounds}

Total condensed tannin was determined with acid butanol assay [10]. In a screw cap culture, $6 \mathrm{ml}$ of the acid butanol reagent was added to a $1 \mathrm{ml}$ aliquot of the sample, followed by addition of $0.2 \mathrm{ml}$ of the iron reagent and vortexing of the sample. The tube was capped loosely, and put in a boiling water bath for $50 \mathrm{~min}$. The tube was cooled and the absorbance was read at $550 \mathrm{~nm}$; the absorbance of a blank containing only sample solvent, acid butanol and iron was subtracted from the sample absorbance. The purified tannin $\mathrm{mg} \mathrm{g}^{-1}$ was used for standard curves.

\section{Determination of Lipid Peroxidation (MDA)}

The level of lipid peroxidation in plant tissues was determined as 2-thio barbituric acid (MDA) reactive metabolites chiefly malomdialdehyde as described previously [3]. Plant tissues $(0.2 \mathrm{~g})$ were extracted in $2 \mathrm{ml}$ of $0.25 \%$ MDA made in $10 \%$ TCA. Extract was heated at $95{ }^{\circ} \mathrm{C}$ for $30 \mathrm{~min}$ and then quickly cooled on ice. After centrifugation at 10,000 g for $10 \mathrm{~min}$, the absorbance of the supernatant was measured at $532 \mathrm{~nm}$. Correction of non-specific turbidity was made by subtracting the absorbance value taken at $600 \mathrm{~nm}$. The level 
of lipid peroxidation is expressed as nmol of MDA formed using an extinction coefficient of $155 \mathrm{mM} \mathrm{cm}^{-1}$.

$$
\begin{aligned}
& \operatorname{MDA}\left(\mathrm{nmolg}^{-1} \mathrm{fw}\right) \\
&=\left[\left(\mathrm{Abs}_{532}+\mathrm{MDA} \sim \mathrm{Abs} 600+\mathrm{MDA}\right) /\right. \\
&(\text { Abs532 }-\mathrm{MDA} \sim \mathrm{Abs600}-\mathrm{MDA})] / \\
& 155 * 103 / \text { amount of sample }(\mathrm{g}) .
\end{aligned}
$$

Statistical Analyses

Two-factor factorial ANOVA was used to compare TGSH, nonprotein thiols. Leaves and root parameters in two cultivars were compared using SPSS software (version 13).

\section{Results}

Changes in the Levels of $\mathrm{Al}$

The total $\mathrm{Al}^{3+}$ concentration in the seedlings of both cultivars increased with increasing $\mathrm{Al}^{3+}$ level in the medium culture (Tables 1 and 2; $P<0.005$ ). However, the amount of $\mathrm{Al}^{3+}$ in leaves of cultivar 132 was higher than that in cultivar 552 (Table $2 ; P<0.005$ ). The $\mathrm{Al}^{3+}$ concentration in the roots was much higher than that in the leaves, indicating that the root is the main part for $\mathrm{Al}^{3+}$ accumulation in a sorghum plant. The cultivar 552 had the higher $\mathrm{Al}^{3+}$ accumulation when treated with 10,20 , and $30 \mathrm{mg}^{-1} \mathrm{Al}^{3+}$, which may be attributed to the highest $\mathrm{Al}^{3+}$ concentration in roots and lower root DWduring the treatment (Table 2; $P<0.005$ ).

\section{Cultivars Leave DW and Leaves Expansion}

A gradual decrease in total DW was observed with the increase in $\mathrm{Al}^{3+}$ concentration (Fig. 1; Table 1, $P<0.001$ ). $\mathrm{Al}^{3+}$ in low concentration $\left(10 \mathrm{mg} \mathrm{l}^{-1}\right)$ leaf area (LA) in cultivar 132 and dry weight leaves (DWL) in cultivar 552 were significantly increased (Table $1 ; \mathrm{f}(3,3)=12$; $P<0.001$; Fig 1a and b). Leaf expansion in cultivar 132 (3.08 $\mathrm{m}^{-2}$; Fig. 1b) was higher than that in cultivar 552 $\left(2.67 \mathrm{~m}^{-2}\right)$. In comparison with the control, a significant

\begin{tabular}{|c|c|c|c|c|c|}
\hline \multirow[t]{2}{*}{ Treatment } & \multicolumn{2}{|c|}{ Roots } & \multicolumn{2}{|c|}{ Leaves } & \multirow[t]{2}{*}{ Medium culture } \\
\hline & 132 & 552 & 132 & 552 & \\
\hline Control & $6^{\mathrm{bc}}$ & $7.2^{\mathrm{c}}$ & $2^{\mathrm{a}}$ & $3^{\mathrm{ab}}$ & $2^{\mathrm{a}}$ \\
\hline $\mathrm{AL} 10 \mathrm{mg} \mathrm{l}^{-1}$ & $65^{\mathrm{h}}$ & $59^{\mathrm{g}}$ & $21^{\mathrm{d}}$ & $18^{\mathrm{d}}$ & $80^{\mathrm{i}}$ \\
\hline Al $20 \mathrm{mg}^{-1}$ & $86^{\mathrm{i}}$ & $97^{\mathrm{j}}$ & $35^{\mathrm{e}}$ & $32^{\mathrm{e}}$ & $102^{\mathrm{j}}$ \\
\hline $\mathrm{Al} 30 \mathrm{mg} \mathrm{l}^{-1}$ & $110^{\mathrm{k}}$ & $148^{1}$ & $56^{\mathrm{g}}$ & $41^{\mathrm{f}}$ & $210^{\mathrm{m}}$ \\
\hline
\end{tabular}
decrease in DW leaves and roots was observed at
Table 2 Changes in aluminum concentration in roots, leaves, and medium culture of cultivars 132 and 552, 30 days after sowing

The $\mathrm{Al}$ concentration is expressed as $\mathrm{mg}^{-1}$ dry weight. The values are the means of four concentrations. Within the all treatment concentration, mean values followed by different letters $(a, b$, and $c)$ are significantly different $(P<0.05)$

A
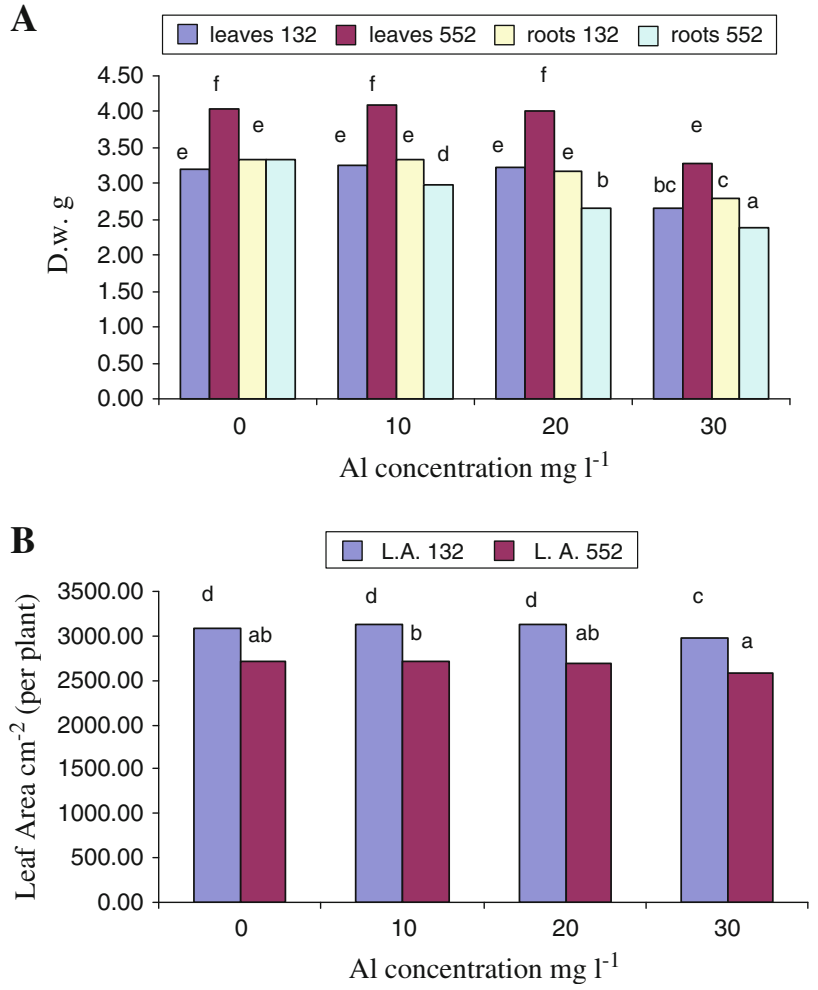

Fig. 1 Effects of $\mathrm{Al}^{3+}$ on dry weight (DW) leaves and roots (a) and leaves area per plant (b) in sorghum plants grown in medium solution containing different concentration of $\mathrm{AlCl}_{3}$. data are mean $\pm \mathrm{SD}$ of four replicates. The treatment mean values followed by different

\begin{tabular}{|c|c|c|c|c|c|c|c|c|c|}
\hline Factor & Df & DWL & DWR & LA & TPC & TGSH & Tannin & PAL & MDA \\
\hline Treatment & 3 & 2.3 & $3^{*}$ & 2.1 & $4.1 * *$ & 2 & 2.7 & 1.1 & 1.6 \\
\hline Cultivar & 1 & $6.3 * * *$ & $5 * *$ & $11 * * *$ & $4.2 * *$ & $7 * * *$ & $9 * * *$ & $5 * *$ & $3.2^{*}$ \\
\hline $\mathrm{Al}$ & 3 & $12 * * *$ & $9 * * *$ & $10 * * *$ & $14 * * *$ & $17 * * *$ & $14 * * *$ & $8 * * *$ & $7 * * *$ \\
\hline Cultivar*Al & 3 & $7 * *$ & 2 & $4.3 * *$ & $7 * * *$ & $8 * * *$ & $6^{* *}$ & $4 * *$ & $4.2 * *$ \\
\hline Error & 22 & & & & & & & & \\
\hline
\end{tabular}
letters $(a, b$, and $c)$ are significantly different $(P<0.05)$

Table $1 F$-values from analysis of variance for the effects of $\mathrm{Al}^{3+}$ and cultivars on leaves area (LA), DWL, dry weight roots (DWR), LA, phytochelatin (PC), TGSH, tannin, phenylalanine-ammonialyase (PAL), and lipid peroxidation (MDA) in leaves

$F$-values with their probability: $* * * P<0.001, * * P<0.01, * P<0.05$ 
$30 \mathrm{mg} \mathrm{l^{-1 }} \mathrm{Al}^{3+}$. The decrease in DW of roots was higher than leaves $(P<0.005)$. Compared with the controls, at $30 \mathrm{mg} \mathrm{l}^{-1} \mathrm{Al}^{3+}$, the DW in leaves and roots of cultivar 132 decreased approximately by 17 and $23 \%$, respectively. In cultivar 552, the leaf DW decreased by $26 \%$ when treated with $30 \mathrm{mg} \mathrm{l}^{-1} \mathrm{Al}^{3+}$, whereas the equivalent reduction for roots was $32 \%$ (Fig. 1a).
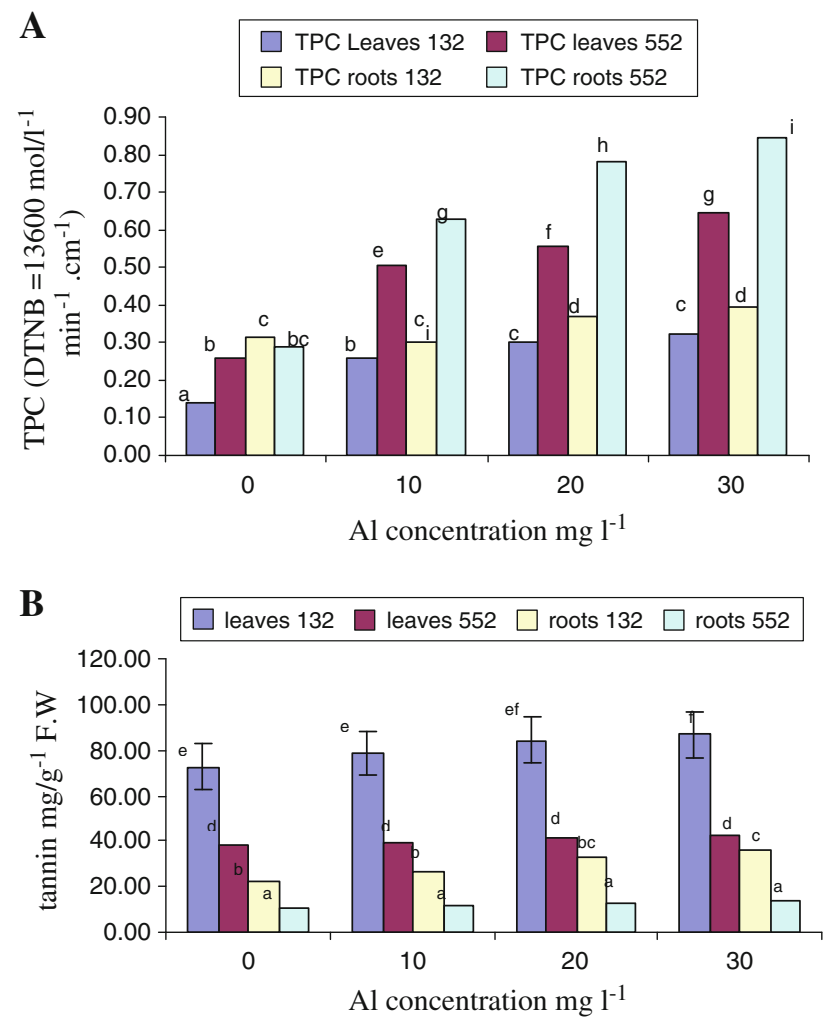

C

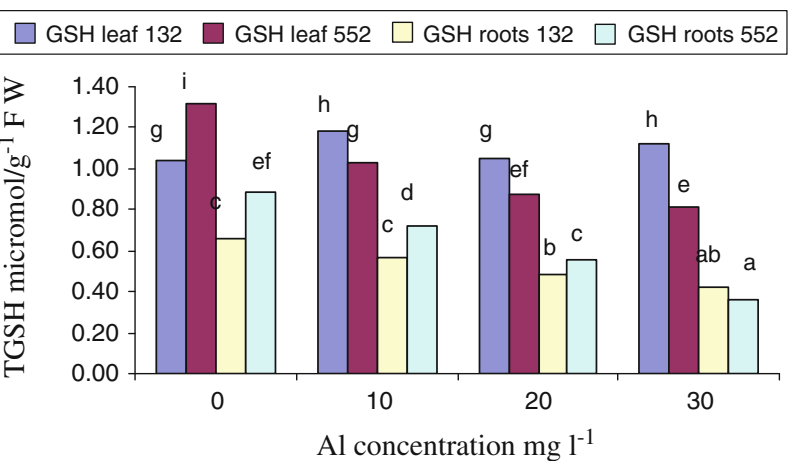

Fig. 2 Effects of $\mathrm{Al}^{3+}$ on TPC $\left(€_{\mathrm{DTNB}}=13,600 \mathrm{~mol} \mathrm{l}^{-1}\right.$ $\left.\min ^{-1} \mathrm{~cm}^{-1}\right)(\mathbf{a})$, tannin $\left(\mathrm{mg} \mathrm{g}^{-1} \mathrm{DW}\right)(\mathbf{b})$ and TGSH $\left(\mu \mathrm{molg}^{-1} \mathrm{FW}\right)$ (c) in leaves and roots of sorghum plants grown in medium solution containing different concentration of $\mathrm{AlCl}_{3}$. Data are mean $\pm \mathrm{SD}$ of four replicates. The treatment mean values followed by different letters $(a, b$, and $c)$ are significantly different $(P<0.05)$
Total Glutathione (TGSH)

The concentrations of TGSH in leaves and roots were significantly different depending upon cultivars and $\mathrm{Al}^{3+}$ treatment (Fig. 2c; Table 1). With increase of $\mathrm{Al}^{3+}$ concentration, there was decrease in the amount of TGSH: $5 \%$ in leaves and $53 \%$ in roots of cultivar 132 (Fig. 2c; $P<0.005)$. However, in cultivar 552, $\mathrm{Al}^{3+}$ stress caused a significant decrease $(73 \%)$ in TGSH in roots and $47 \%$ in leaves. The amount of TGSH in cultivar 552 was higher than that in cultivar 132 (Fig 2c; $P<0.005$ ).

\section{Total Phytochelatins (TPC)}

The TPC in roots and leaves of two cultivars was significantly increased with increasing $\mathrm{Al}^{3+}$ concentration (Fig. 2a; Table 1; $P<0.005$ ). The levels of TPC were increased by $70 \%$ in roots and about $36 \%$ in leaves of cultivar 132, and those of TPC were increased by $98 \%$ in roots and about $78 \%$ in leaves of cultivar 552 .

\section{Changes in Tannin}

Evidence indicates that, tannins' contents in cultivars significantly increased in all treatments under $\mathrm{Al}^{3+}$ concentration (Fig. 2b; Table 1; $P<0.005$ ). With comparison of means the concentration of total tannins in leaves was about (cultivar 132, $60.22 \mathrm{mg} \mathrm{g}^{-1}$ and cultivar 552, $23.17 \mathrm{mg} \mathrm{g}^{-1}$ ) increased (Table 2).

\section{Change in PAL Activity (EC 4.3.1.5)}

The results showed that activity of PAL significantly increased in the leaves of two cultivars (Fig. 3a; Table 1; $P<0.005)$ in response to $\mathrm{Al}^{3+}$, with cultivar 132 having higher PAL activities than those of cultivar 552. There was an increase in the concentration of PAL in the leaves (when comparing the mean values) from $73.41 \mu \mathrm{mol} \mathrm{g}^{-1}$ Cinnamic acid F.W in cultivar 132; and $43.52 \mu \mathrm{mol} \mathrm{g}^{-1}$ Cinnamic acid FW in cultivar 552; Fig. 3a) Compared with the controls, at $30 \mathrm{mg} \mathrm{l}^{-1} \mathrm{Al}^{3+}$, the PAL activities in the roots of two cultivars increased approximately by $50 \%$ (Fig 3a; Table 1; $P<0.005$ ). PAL activity was lower in cultivar 552 than that in cultivar 132 .

\section{Change in Glutathione-s-Transferees Activity (EC 2.5.1.18)}

Results in Fig. 3b showed that the activity of GST significantly increased in the leaves of two cultivars (Fig. 3b; Table $1 ; P<0.005)$ in response to $\mathrm{Al}^{3+}$. Cultivar 552 was found to have higher GST activity than cultivar 132 . There 

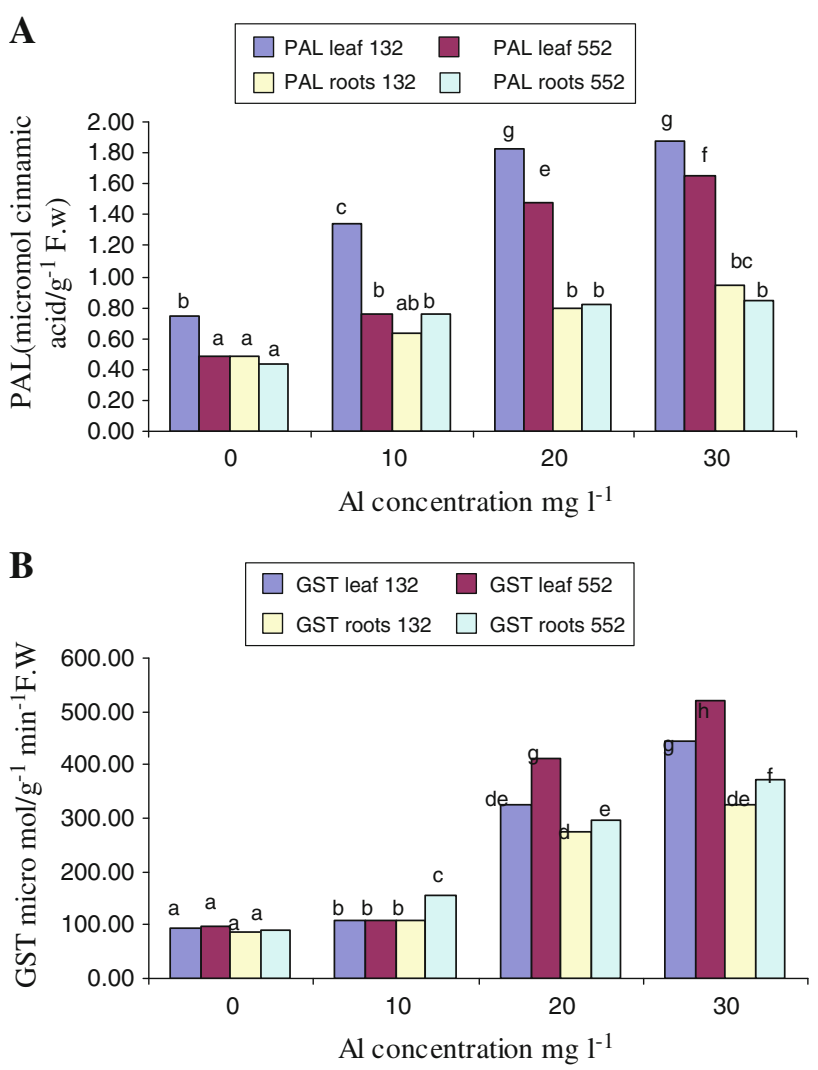

Fig. 3 Effects of $\mathrm{Al}^{3+}$ on activities of PAL ( $\mu$ mol cinnamic acid $\left.\mathrm{g}^{-1} \mathrm{~h}^{-1} \mathrm{FW}\right)(\mathbf{a})$, GST $\left(\mu \mathrm{mol} \mathrm{g}{ }^{-1} \mathrm{~min}^{-1} \mathrm{FW}\right)(\mathbf{b})$ in leaves and roots of sorghum plants grown in medium solution containing different concentration of $\mathrm{AlCl}_{3}$. Data are mean $\pm \mathrm{SD}$ of four replicates. The treatment mean values followed by different letters $(a, b$, and $c)$ are significantly different $(P<0.05)$

was increase in the concentration of GST in leaves (when comparing the mean values) by $285.7 \mu \mathrm{mol} / \mathrm{g}^{-1} \mathrm{~min}^{-1}$ protein $\mathrm{t}$ in (cultivar 552, and $243.1 \mu \mathrm{mol} / \mathrm{g}^{-1} \mathrm{~min}^{-1}$ protein in cultivar 132; Fig. 3b). Compared with the controls, at $30 \mathrm{mg} \mathrm{l}^{-1} \mathrm{Al}^{3+}$, the GST activities in roots of cultivars 552 and 132 increased by approximately 98 and $80 \%$, respectively (Fig $3 \mathrm{~b}$; Table $1 ; P<0.005$ ).

\section{Change in Lipid Peroxidation (MDA)}

Results in Fig. 4 showed that the levels of MDA significantly increased in leaves of two cultivars (Fig. 4; Table 1 $P<0.005)$ in response to $\mathrm{Al}^{3+}$. MDA content in new leaves of $\mathrm{Al}^{3+}$-treated cultivar 552 was significantly higher than that in cultivar 132. The results showed a significant increase that was more pronounced in leaves than in roots of the $\mathrm{Al}^{3+}$-treated cultivars. In high concentrations of $\mathrm{Al}^{3+}\left(20\right.$ and $\left.30 \mathrm{mg} \mathrm{l}^{-1}\right)$, MDA in the leaves of cultivar 552 was increased and consequently influenced the glutathione's content in cultivars 552 (Fig. 4).

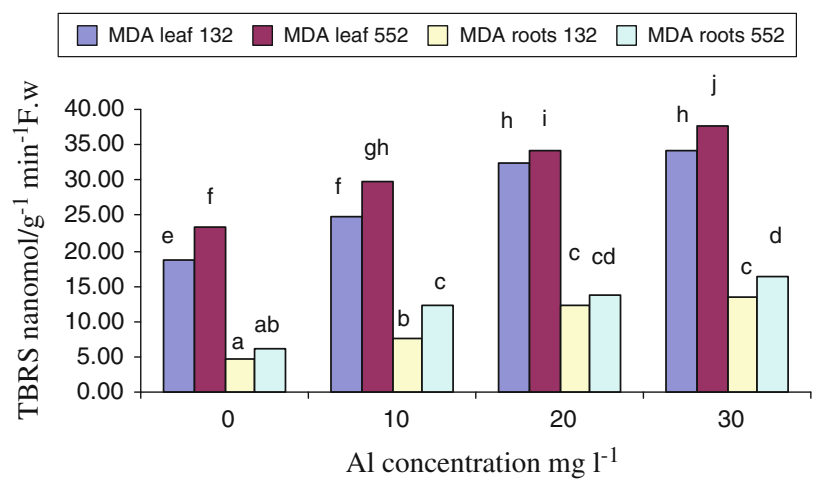

Fig. 4 Effects of $\mathrm{Al}^{3+}$ on MDA (TBRS $\eta \mathrm{mol} \mathrm{g}^{-1} \min { }^{-1} \mathrm{FW}$ ) in leaves and roots of sorghum plants grown in medium solution containing different concentration of $\mathrm{AlCl}_{3}$. Data are mean $\pm \mathrm{SD}$ of four replicates. The treatment mean values followed by different letters $(a, b$ and $c)$ are significantly different $(P<0.05)$

\section{Correlation Between TPC and TGSH}

The TPC represent the all groups of sorghum leaves phytochelatins, and their concentrations have been shown to correlate positively with TGSH of the leaves and roots in cultivar 552 (Table 3, leaves; $\mathrm{R}^{2}=97 ; \mathrm{y}=0.38 \mathrm{x}+.55$ and roots; $\left.\mathrm{R}^{2}=87 ; \mathrm{y}=1.02 \mathrm{x}+.1 .28, P<0.005\right)$. The changes in correlation coefficients in the TPC and TGSH with increased concentrations of $\mathrm{Al}^{3+}$ in leaves in cultivars 132 were not significant. (Table 3, leaves; $\mathrm{R}^{2}=16 ; \mathrm{y}=0.47 \mathrm{x}+.29$ and roots; $\left.\mathrm{R}^{2}=97 ; \mathrm{y}=-0.3 \mathrm{x}+.0 .55, P<0.005\right)$. No significant correlation was noted between TPC and TGSH of the leaves in cultivar 132 (Table 3; $P<0.005$ ).

\section{Correlation Between TPC and GST Activity}

There was a direct correlation between the activities of GST and the concentration of TPC in the leaves and roots in cultivar 552 (Table 3 , leaves; $\mathrm{R}^{2}=85 ; \mathrm{y}=-0.0097 \mathrm{x}+$ 1.26 and roots; $\mathrm{R}^{2}=98 ; \mathrm{y}=-.0 .001 \mathrm{x}+1.02, \quad P<$ 0.005). Correlations between the changes in the amount of TPC per leaf and GST activity were mostly non-significant in the leaves of cultivar 132, but in the roots, they were significant (Table 3, leaves; $\mathrm{R}^{2}=0.16 ; \mathrm{y}=0.47 \mathrm{x}+0.29$ and roots; $\left.\mathrm{R}^{2}=0.81 ; \mathrm{y}=-0.38 \mathrm{x}+0.55+1.02, P<0.005\right)$.

\section{Correlation Between TGSH and GST Activity}

A positive relationship was found between GST activity and TGSH in the roots of two cultivars (Table 3, roots $132 ; \mathrm{R}^{2}=0.98 ; \mathrm{y}=0.0 .0026 \mathrm{x}+0.16$ and roots 552; $\left.\mathrm{R}^{2}=0.8 ; \mathrm{y}=-0.0021 \mathrm{x}+0.21, P<0.005\right)$. There was significant correlation between GST activity and TGSH of the leaves in two cultivars (Table 3, leaves $132 ; \mathrm{R}^{2}=0.8$; $\mathrm{y}=0.002 \mathrm{x}+0.16$ and leaves $552 ; \mathrm{R}^{2}=0.75 ; \mathrm{y}=$ $-0.001 \mathrm{x}+0.21, P<0.005)$. 


\section{Discussion}

Sorghum (Sorghum bicolor L.) serves as staple food for the majority of world population and its productivity is drastically limited under environmental stress. The possible mechanisms of effectiveness and protection against the metal toxicity is by enzymatic action and extending our knowledge about the antioxidant process, especially in different organs, which could provide information regarding the regulation of this process [21]. In this study, two sorghum cultivars differing in leaves and roots $\mathrm{Al}^{3+}$ accumulation according to a previous study was selected. The cultivar 552 grown at $30 \mathrm{mg} \mathrm{l}^{-1} \mathrm{Al}^{3+}$ was moderately chlorotic, exhibiting brown lesions on the leaves and appearing noticeably smaller than controls. Roots of $\mathrm{Al}^{3+}$ treated cultivar 552 generally appeared darker than control plants, perhaps $\mathrm{Al}^{3+}$ stimulated efflux of phenolic and organic acids, due to the fact that the surface of roots was darker, but the cultivar 132 grown at $30 \mathrm{mg} \mathrm{l}^{-1}$ was low chlorotic, appearing slightly smaller than controls [20], [21], [24] and [32]. Various phenotypic symptoms in response to heavy metal stress include reduced leaf expansion, chlorosis that may lead to necrosis. Despite the ability of the cultivars to reduce $\mathrm{Al}^{3+}$ toxicity, the concentration of $\mathrm{Al}^{3+}$ in the growth medium was almost higher than concentration of $\mathrm{Al}^{3+}$ in the roots, and in the leaves (Table 2). The $\mathrm{Al}^{3+}$ was accumulated mainly in old leaves in cultivars during the growth, and the amount in young leaves of cultivars was very low $[19,22]$. The distribution of $\mathrm{Al}^{3+}$ between the roots fractions of cultivar 132 and cultivar 552 is shown in Table 2. Most of the $\mathrm{Al}^{3+}$ was retained in the roots, an average of $78.4 \%$ of $\mathrm{Al}^{3+}$ in the cultivar 552 roots and $60.5 \%$ of $\mathrm{Al}^{3+}$ in the cultivar 132 roots was found in the roots fraction. $\mathrm{Al}^{3+}$ decreases DW of the leaves, roots and leaf area in two cultivars, and the DW decrease in $30 \mathrm{mg} \mathrm{l}^{-1} \mathrm{Al}^{3+}$ was higher than that other $\mathrm{Al}^{3+}$ concentrations (Fig. 1; Table 1). The results showed agreement with the previous study [17]. In $\mathrm{Al}^{3+}$ stress, the dry weight partitioning between roots and leaves was significantly changed, at high concentrations of $\mathrm{Al}^{3+}$ below ground biomass was high constrained rather than above ground and DW root decreased more than DW leaves (Fig. 1a).

In low concentrations of $\mathrm{Al}^{3+}$, it stimulates the growth in some plants [1]. With increasing concentrations $\mathrm{Al}^{3+}$ in medium cultural till $10 \mathrm{mg} \mathrm{l}^{-1}$, the DW of the leaves and leaf area in cultivar 132 were increased, but only DWL in cultivar 552 was increased (Fig. 1a, b). This experiment showed that low accumulation of $\mathrm{Al}^{3+}$ in leaves of two cultivars may be a strategy to protect photosynthetic function from the induced oxidative stress [24]. The cultivars can avoid $\mathrm{Al}^{3+}$ damage, which emerged in the presence of $30 \mathrm{mg} \mathrm{l}^{-1}$ of the $\mathrm{Al}^{3+}$, and can develop defense mechanisms to cope with the affinity of $\mathrm{Al}^{3+}$ for TPC and tannin. In the present study, in roots of cultivars, the amount of $\mathrm{Al}^{3+}$ in the roots was increased continuously, and the $\mathrm{Al}^{3+}$ concentration in leaves of cultivar 132 was higher than cultivar 552 , but $\mathrm{Al}^{3+}$ concentration in the roots cultivar 132 was lower than cultivar 552 (Table 2). This agrees with previous findings in sorghum and in other plants [7], [17] and [22].

The TPC increased by $98 \%$ from the first concentration to $30 \mathrm{mg} \mathrm{l}^{-1} \mathrm{Al}^{3+}$ in the roots cultivar 552 (Fig. 2a). By contrast, TGSH decreased by $73 \%$ in cultivar 552 from the first concentration to the $30 \mathrm{mg} \mathrm{l}^{-1} \mathrm{Al}^{3+}$ (Fig. 2b). In cultivar 132, TPC increased by $70 \%$ from the first concentration to the $30 \mathrm{mg} \mathrm{l}^{-1} \mathrm{Al}^{3+}$ in roots. By contrast, TGSH decreased by $53 \%$ in cultivar 132 from the first concentration to the $30 \mathrm{mg} \mathrm{l}^{-1}$ (Fig. 2a, c), agreement with the observed [8], [26]. In the present study, the threshold $\mathrm{Al}^{3+}$ exposure levels for root growth inhibition and TPC accumulation coincide in two cultivars (Fig. 2a, c; Table 2). Although $\mathrm{Al}^{3+}$ induces TPC accumulation, the capacities of the two cultivars in antioxidant and TPC accumulation in the roots and leaves were different (Fig. 2a). The amounts of TPC in the leaves and roots of cultivar 552 were higher than those in cultivar 132, but the amounts of tannins in the leaves and roots of cultivar 552 werelower than those of cultivar 132 (Fig. 2b). Following $\mathrm{Al}^{3+}$ stress, a deep alteration of the TGSH status occurred mainly in the leaves and roots of cultivar 552. The TGSH is used as substrate for TPC production. Therefore, TPC may

Table 3 The correlation coefficient and regression equations between TGSH, and GST activities in the leaves and roots of two cultivars of sorghum plants exposed to different concentration of $\mathrm{AlCl}_{3}$

\begin{tabular}{|c|c|c|c|c|c|c|c|c|}
\hline \multirow{3}{*}{$\begin{array}{l}\text { Trait pair } \\
\mathrm{X} \text { and } \mathrm{Y}\end{array}$} & \multicolumn{8}{|c|}{ Activities } \\
\hline & \multicolumn{2}{|c|}{ Leaves 132} & \multicolumn{2}{|c|}{ Roots 132} & \multicolumn{2}{|c|}{ Leaves 552} & \multicolumn{2}{|c|}{ Roots 552} \\
\hline & $\mathrm{R}^{2}$ & Equation & $\mathrm{R}^{2}$ & Equations & $\mathrm{R}^{2}$ & Equations & $\mathrm{R}^{2}$ & Equation \\
\hline GST and TPC & 0.02 & $Y=-2 x+1.1$ & 0.95 & $\mathrm{Y}=-0.001 \mathrm{X}+0.7$ & 0.85 & $Y=-0.009+1.26$ & 0.98 & $\mathrm{Y}=-0.001 \mathrm{X}+1.02$ \\
\hline GST and TGSH & 0.8 & $Y=0.002 X+0.16$ & 0.98 & $Y=0.001 X+0.26$ & 0.75 & $Y=0.001 X+0.31$ & 0.8 & $Y=0.001 X+0.21$ \\
\hline$G S H$ and $T P C$ & 0.16 & $Y=0.47 X+0.29$ & 0.81 & $Y=-0.38 X+0.55$ & 0.97 & $Y=-0.71 X+1.21$ & 0.87 & $\mathrm{Y}=-1.02 \mathrm{X}+1.28$ \\
\hline
\end{tabular}


be functionally important to cultivars 552 under conditions of $\mathrm{Al}^{3+}$ stress, in agreement with the previous results [32]. The threshold concentration levels of $\mathrm{Al}^{3+}$, for TPC accumulation appeared in the cultivar 552 were lower than the cultivar 132 (Table 2; Fig. 2a). In cultivar 132, the induced TPC accumulation was not apparent until the threshold concentration level of $\mathrm{Al}^{3+}$ for acute toxicity had been exceeded, suggesting that tannins are normally involved in $\mathrm{Al}^{3+}$ sequestration under conditions of sub toxic exposure [22], [32]. It is likely, as previously argued, that $\mathrm{Al}^{3+}$ bound to the cytosolic $\mathrm{SH}$ group dependent enzyme, reduces sucrose synthesis [4].

In two cultivars, $\mathrm{Al}^{3+}$ increased the TPC in roots which has been widely considered as a mechanism whereby these cultivars can acquire a degree of resistance to $\mathrm{Al}^{3+}$ toxicity (Table 2; Fig. 2a).

\section{The Relations Between TPC, TGSH, and $\mathrm{Al}^{3+}$}

In two cultivars, the roots concentration of TPC in $30 \mathrm{mg} \mathrm{l}^{-1} \mathrm{Al}^{3+}$ was significantly higher than the controls (Fig. 2a). The localization of TPC in the roots could provide an effective means of restricting $\mathrm{Al}^{3+}$ to this organ by chelating in the form of Al-SH (TPC) complexes, and the transport to leaves was restricted [6]. A negative correlation was found between TPC and TGSH (Fig. 2a, c). The variation of TGSH in leaves may be influenced by leaf synthesis, as suggested by the significant correlation noted between TGSH and (TGSH + GSSG). However, the correlation between TGSH and (TGSH + GSSG) remained significant after subtracting TPC effect on $\mathrm{Al}^{3+}$ (Fig. 2c). This result was expected, since the relationship between TGSH and (TGSH + GSSG) was scarcely documented [5]. The TGSH is a central metabolic and is involved in the reaction forming TPC [12]. The statistical analysis shown indicated that both TGSH and TPC exhibited in two cultivars, a high degree of variability as shown by the (Fig. 2a, c). This variability has been caused by the differences due to cultivars variety in antioxidants and tannin in leaves and roots (Fig. 2b, Fig. 4). In cultivar 132 leaves, $\mathrm{Al}^{3+}$ treatment increased total tannin's content, mediated by enhanced activity of PAL (Figs. 2b, 3a), but in cultivar 552 , the total tannin was low and consequently the activity of PAL was low (Fig. 3a). In cultivar 552, TGSH contents were higher than those in cultivar 132 , and $\mathrm{Al}^{3+}$ treatment increased TGSH content, mediated by enhanced activity of GST (Fig. 2c, 3b; and Table 3). The TGSH contents may have been consumed for two strategies: the maintenance of regular redox potential, and the precursor for TPC synthesis, in agreement with the previously observed results [18].

The major effect observed in this research was that $30 \mathrm{mg} \mathrm{l}^{-1}$ of $\mathrm{Al}^{3+}$ in medium culture, the TGSH level by about $47 \%$ in leaf cultivars 552 and by about $5 \%$ in leaf cultivar 132 were decreased Fig. 2c, in agreement with the previousluy observed data [30]. Therefore, in cultivar 552 leaves parallel to the transient depletion of TGSH which is used as substrate for TPC production, the synthesis of TGSH seem accurse. The result in cultivar 132 has shown that the level of antioxidant regulated by TGSH content and parallel to the transient depletion of TGSH does not seem for TPC production (Fig. 2a, c; and Table 3). Also the distribution of TPC in the roots and leaves of cultivar 132 were different, in agreement with the previously observed behaviors [5], [18].

It also explains in cultivar 552 why, in $\mathrm{Al}^{3+}$-treated leaves the pool of TGSH decreased. In cultivar 552, the amount of tannin was very low, and this cultivar needed quantitatively to maintain as much in reduced forms. The high cost of this activity could be mitigated by using TPC in antioxidant activity against $\mathrm{Al}^{3+}$. TGSH can mobile to many organs in plants, and this characteristic is very useful for an antioxidant [26]. Furthermore, TGSH efficiently lowers the probability that $\mathrm{Al}^{3+}$ will bind to $\mathrm{SH}$ in the active sites of many photosynthetic enzymes, which would alter their functionality and inhibit photosynthesis [17]. This was a predictable result because it is known that $\mathrm{Al}^{3+}$ acts as a strong sink for $\mathrm{SH}$ grope, which increases the demand for sulfate absorption. The predominance of the TPC, this confirms the suggestion that $\mathrm{SH}$ grope can trap $\mathrm{Al}^{3+}$ only when they are in the reduced state [14].

The amount of TGSH in cultivar 552 was higher than cultivar 132, this difference in two cultivars, may be due to the synthesis of TGSH in the leaves and roots, or recycling of TGSH in the roots and leaves. It has been suggested that cultivar 552 with high TGSH concentration may improve their growth and antioxidant resistance under $\mathrm{Al}^{3+}$ excess, therefore TGSH regeneration by the Glutamin-Glutamat cycle is a key antioxidant mechanism against $\mathrm{Al}^{3+}$ stresses [8]. therefor the first toxicity of $\mathrm{Al}^{3+}$, in cultivar 552 antioxidant compounds such as TGSH with rapid turnover and high cumulative to be cost effective than tannin for leaves because tannin was low and stable. In cultivar 132, antioxidant compounds such as tannin with low turnover and high accumulation, seem to be more cost effective than TGSH for leaves, because the leaf toughness in cultivar 552 was higher than cultivar 132 [13], [22]. In cultivar 552, TGSH can mobile between roots and leaves, for this reason the amount of TGSH in the control leaves of cultivar 552 was high. In cultivar 132, the tannin can not mobile between roots and leaves [32].

In cultivar 552, when the $\mathrm{Al}^{3+}$ concentration was increased, the transformation of TGSH to TPC was high, but in cultivar 132, when the $\mathrm{Al}^{3+}$ concentration was increased, the synthesis of tannin was increased, and the transformation of TGSH to TPC was very low. The 
transformation of TGSH in cultivar 552 was much higher than the rate of synthesis, however, in cultivar 132 the rate of transformation was lower than the rate of synthesis. Therefore loss of TGSH due to $\mathrm{Al}^{3+}$ stress in cultivar 132 was lower than cultivar 552, agreement with the observed [18].

The Relation Between TPC, TGSH, MDA, and Tannin and GST and PAL Activities

Changes in chemical defenses including tannins and various activities MDA and GST in the presence of $\mathrm{Al}^{3+}$ in the leaves and roots of cultivars were investigated. MDA is the marker for lipid peroxidation increase in metal stress [27]. $\mathrm{Al}^{3+}$ increased MDA activity in two cultivars, which coincided with a high decrease of TGSH, in roots (Fig 2c, Fig.4). With the increase of the concentrations of $\mathrm{Al}^{3+}$, activities of GST were increased in the leaves of two cultivars, and increase in cultivar 552 was higher than that in cultivar 132 (Fig. 3b). With increasing $\mathrm{Al}^{3+}$ concentrations, the amount of tannins in the leaves of two cultivars increased, and the increase in cultivar 132 was higher than that in cultivar 552 (Fig. 2b). When cultivar 552 was exposed to $\mathrm{Al}^{3+}$, the equilibrium between production tannins and TGSH was broken, resulting in oxidative damage; increased allocation to TGSH which are potential antioxidant compounds markedly increased the activity of GST enzyme, while MDA activity greatly increased as compared with control (Fig. 4 and Table 3). Thus, balance between MDA and TGSH generation and scavenging compound tannins in leaves may reflect the defense strategy in two cultivars [33].

Tannins are derived from polyphenols, which are formed from phenylalanine by the activity of PAL. Thus, PAL is often speculated to be a key enzyme in tannins metabolism (Figs. 2b, 3a). The PAL enzyme can readily be induced by some environmental stresses [21]. Thus, we examined the possibility that PAL activity might be induced by concentration of $\mathrm{Al}^{3+}$. Figure 4 indicates that, with increased $\mathrm{Al}^{3+}$ concentrations in medium culture, in cultivar 552 the activity of PAL increased and reached to a maximum value. But in cultivar 132, the increase in the activity of PAL was higher than that in cultivar 552. On the other hand, the amount of tannin in cultivar 132 increased with increasing concentrations of $\mathrm{Al}^{3+}$. These results indicate that an increase in tannin in cultivar 132 is based on an increase in the activity of PAL (Figs. 2b, 3a). Also, in cultivar 552, the enhanced formation of TPC during TGSH depletion is preceded by an increase in $\mathrm{Al}^{3+}$ concentrations. The decrease in TGSH in cultivar 552 is dependent on an increase in the activity of GST enzyme and subsequent lowering of PAL activity (Fig. 3a and Table 3). The results are consistent with the previous observations [19], [20] and [34]. Cultivar 132 exhibited a maximum value of PAL activity, which is two times higher than that of cultivar 552 and minimum of TGSH. Upon treatment with $10 \mathrm{mg} \mathrm{l}^{-1} \mathrm{Al}^{3+}$, the activity of PAL was not significantly altered in cultivar 552-rather it increased in cultivar 132 (Fig. 3a).

In the experiment, the increase in PAL activity might be controlled by either antioxidant potential of cells or activation by $\mathrm{Al}^{3+}$. One of the mechanisms for the tolerance in cultivar 132 seems to be the accumulation of antioxidant molecules such as tannin which inhibits the facilitation of the peroxidation of phospholipids [11], [19].

Regarding the result obtained in this experiment, two strategies for $\mathrm{Al}^{3+}$ resistance in two cultivars have been suggested. First, the increase in tannins is responsible for the formation of phenoxy radicals. These metabolites may participate in ROS scavenging through antioxidant activity or can be directly chelated $\mathrm{Al}^{3+}$. It has been well documented that $\mathrm{Al}^{3+}$ stresses are responsible for the increase in tannins which would be antioxidant and associated with decreased plant growth [23], [31].

Second, the changes that occurred, in the pathway of TGSH synthesis and TPC metabolism of the leaves and roots, indicated the establishment of the fact that TGSH metabolism was very active with high activation of MDA (Fig. 4). The data obtained from the $\mathrm{Al}^{3+}$ stresses suggest that the increased activities of GST and PAL are among the important factors of tolerance for $\mathrm{Al}^{3+}$ which permits preservation of membrane integrity and leaf growth (Fig. 3a, Fig. 4).

The observed increases in the activities of PAL and GST in two cultivars might indicate extensive lipid peroxidation of cell membrane. Significant decreases in DW occurred following the $30 \mathrm{mg} \mathrm{l}^{-1} \mathrm{Al}^{3+}$ treatment, which coincided with the increases in MDA, tannin, and TPC (Fig. 2a, b and Table 3). The induction of total tannins and changes in the contents of TGSH in the leaves of two cultivars play respective important roles in resistance to $\mathrm{Al}^{3+}$, which are intimately connected with GST and PAL activities (Fig. 3a and Table 3). These results agree with the general theory that, when plants are exposed to metals, they switch from normal primary metabolism to the multitude of secondary metabolism pathways, and the activation processes of novel stresses in enzymes and genes take place [29]. Therefore, the potent antioxidant properties of tannins in cultivar 132 are a common response to $\mathrm{Al}^{3+}$ resistance, resulting in enhanced resistance to $\mathrm{Al}^{3+}$ by tannin (Fig. 2b) [32]. The $\mathrm{Al}^{3+}$-treated cultivars 552 caused the highest GST activity, while $\mathrm{Al}^{3+}$-treated cultivar 132 was having the highest PAL activity. It seems that intensive activity of GST coupled with the small changes in tannins during the $\mathrm{Al}^{3+}$ stresses. The production of tannins caused an increase in the antioxidant activity; therefore activation of GST in cultivar 132 was lower than that in cultivar 552 (Fig. 2b and Table 3). 


\section{Conclusion}

Plants respond to $\mathrm{Al}^{3+}$ toxicity in a variety of ways. $\mathrm{Al}^{3+}$ increased allocation to tannins, TGSH, and TPC which are potential defensive compounds. When the two cultivars were analyzed, the behaviors of the compounds of TPC, TGSH, and tannin, and the PAL and GST activities were different in the roots and leaves. In cultivar 132, the involvement of tannins was more than of TPC and TGSH in the reactions triggered by $\mathrm{Al}^{3+}$; therefore, the TPC in the leaves remained low and activation of GST in cultivar 132 was lower than that in cultivar 552. There was a high TPC concentration and a decrease of TGSH in the leaves of cultivar 552. It is probably a combination of multiprocesses that were involved being responsible to cause $\mathrm{Al}^{3+}$ resistance. The TPC synthesis induces TGSH depletion in the leaves of cultivars. It was concluded that this decrease in cultivar 552 is caused by different routes of carbon channeling (TGSH) translocation from leaves to roots, to enable a larger amount of precursor to be available for TPC synthesis in roots, resulting in changes in TGSH metabolism in the leaves.

Open Access This article is distributed under the terms of the Creative Commons Attribution License which permits any use, distribution, and reproduction in any medium, provided the original author(s) and the source are credited.

\section{References}

1. Ahn SJ, Sivaguru M, Chung GC, Rengel Z, Matsumoto H (2002) Aluminium-induced growth inhibition is associated with impaired efflux and influx of $\mathrm{H}$ across the plasma membrane in root apices of squash (Cucurbita pepo). J Environ Qual 53:1959-1966

2. Bores W, Heller C, Michel K (1996) Flavonoids and polyphenol: chemistry and biology, antioxidants. Marcel Dekker, New York, pp 409-466

3. Chien H-F, Wang J-W, Lin CC, Kao CH (2001) Cadmium toxicity of rice leaves is mediated through lipid peroxidation. Plant Growth Regul 33:205-213

4. Cobbett CS (2000) Phytochelatin biosynthesis and function in heavy-metal detoxification. Curr Opin Plant Biol 3:211-216

5. De Vos, Vonk MJ, Vooijs R, Schat H (2001) Glutathione depletion due to copper-induced phytochelatin synthesis causes oxidative stress in Silene cucubalus. Plant Physiol 98:853-858

6. Dejene E, Angelika S, Walter JH (2005) Localization of aluminium in the maize root apex: can morin detect cell wall-bound aluminium. J Exp Bot 56(415):1351-1357

7. Delhaize E, Ryan PR (1995) Aluminum toxicity and tolerance in plants. Plant Phsyiol 107:315-321

8. Ezaki B, Suzuki M, Motoda H, Kawamura M, Nakashima S, Matsumoto H (2004) Mechanism of gene expression of arabidopsis glutathione S-transferase, AtGST1, and AtGST11 in response to aluminum stress. Plant Physiol 134:1672-1682

9. Foyer Ch, Theodoulou FL, Delrot S (2001) The functions of inter-and intracellular glutathione transport systems in plants. Trends Plant Sci 6:486-487
10. Gebrehiwot L, Beuselinck RB, Robert CA (2002) Seasonal variations in condensed tannin concentration of three lotus species. Agron J 94:1059-1065

11. Gomez-Vasquez R, Day R, Buschmann H, Randles S, Beeching JR, Cooper RM (2004) Phenylpropanoids, phenylalanine ammonia lyase and peroxidases in elicitor-challenged Cassava (Manihot esculenta) suspension cells and leaves. Ann Bot 94:87-97

12. Grill E, Loeffler S, Winnacker EL, Zenk MH (1989) Phytochelatins, the heavy-metal-binding peptides of plants, are synthesized from glutathione by a specific $\gamma$-glutamylcysteine dipeptidyl transpeptidase (phytochelatin synthase). Proc Natl Acad Sci USA 86:6838-6842

13. Hagerman AE, Carlson DM (1998) Biological responses to tannins and other polyphenols. Recent Res Dev Agric Food Chem 1998(2):689-704

14. Heiss SA, Wachter J, Bogs C, Cobbett T (2003) Rausch, phytochelatin synthase (PCS) protein is induced in Brassica juncea leaves after pro-longed Cd exposure. J Exp Bot 54:1833-1839

15. Hoagland, Arnon DRDI (1950) The water-culture method for growing plants without soil. Calif Agric Exp Stn Circ 347:1-32

16. Hossain MZ, Hossain MD, Fujita M (2006) Induction of pumpkin glutathione s-transferases by different stresses and its possible mechanisms. Biol Plantarum 50:210-218

17. Juan B, Charlotte P (2002) Fast root growth responses, root exudates, and internal detoxification as clues to mechanisms of aluminum toxicity and resistance: a review. Environ Exp Bot 48:75-92

18. Maier EA, Matthews RD, McDowell JA, Walden RR, Ahner BA (2003) Environmental cadmium levels increase phytochelatin and glutathione in lettuce grown in a chelator-buffered nutrient solution. J Environ Qual 32:1356-1364

19. Malmir HA (2010) The relation between phenylalanine ammonia-lyase, polyphenol oxidase activities and Flavonoids, lignin's and toughness in leaves of sorghum (sorghum bicolor) exposed to Zinc .3rd International congress of environmental research, University of Mauritius, Reduit, 16-18 Sept 2010

20. Malmir HA (2010) The relation between antioxidant enzyme, chlorophyll, flavonoids, lignin and toughness in sorghum (sorghum bicolor) exposed to zinc. The 1st annual international conference ibb environmental science \& technology, which will take place at Ibb University, Ibb city, Yemen, 1-3 Aug 2010

21. Malmir HA (2011) Comparison of antioxidant enzyme activities in leaves, stem and roots of sorghum (Sorghum bicolor L.) exposed to chromium (VI). African J Plant Sci 5(5):436-444

22. Malmir HA, Mostajeran A, Almodares A, Asghari A, Afkhami A (2009) The effects of aluminum on fiber and protein bound condensed tannin, polyphenols and some growth index in two sorghum cultivars. Int J Bot 5(1):58-66

23. Mamoudou H, Dick, Riet H (2002) Comparison of content in phenolic compounds, polyphenol oxides, and peroxidase in grains of fifty sorghum varieties from Burkina Faso. J Agric Food Chem 50:3780-3788

24. Matsumoto H (2001) Cell biology of aluminum toxicity and tolerance in higher plants. Int Rev Cytol 200:1-46

25. Moyer RA, Hummer KE, Finn CE, Frei B, Wrolstad RE (2002) Anthocyanins, phenolics and Antioxidant capacity in diverse small fruits: vaccinum, Rubus, and Ribes. J Agric Food Chem 50:519-525

26. Noctor G, Arisi ACM, Jouanin L, Kunert KJ, Rennenberg H, Foyer ChH (1998) Glutathione: biosynthesis, metabolism and relationship to stress tolerance explored in transformed plants. J Exp Bot 49:624-631

27. Olga Bk, Eija VL, Kurtav Fg (2003) Antioxidants, oxidative damage and oxygen deprivation stress: a review. Ann Bot 91(2):179-194 
28. Ortega-Garcia F, Blanco S, Peinado MA, Peragon J (2009) Phenylalanine ammonia-lyase and phenolic compounds in leaves and fruits of Olea europaea L. cv. Picual during ripening. Sci Food Agric 89:398-406

29. Osone Yoko, Masakitateno (2005) Applicability and limitations of optimal biomass allocation models: a test of two species from fertile and infertile habitats. Ann Bot 95:1211-1220

30. Pagliari M, Sanita' di Toppi L (2005) Oxidative stress and phytochelatin characterization in bread wheat exposed to cadmium excess. Plant Physiol Biochem 43:45-54

31. Pekker I, Elisha TO, Mittler R (2002) Reactive oxygen intermediates and glutathione regulate the expression of cytosolic ascorbate peroxidase during iron-mediated oxidative stress in bean. Plant Mol Biol 49:429-438

32. Peter A, Stoutjesdi JK (2001) Possible involvement of condensed tannins in aluminum tolerance of lotus Pendulatus. Aust J Plant Physiol 28(11):1063-1074

33. Singleton VL, Orthofer R, Lamuela-Raventos RM (1999) Analysis of total phenols and other oxidation substrates and antioxidants by means of folin-ciocalteu reagent. Methods Enzymol 299:152-177

34. Tomas-Barberan F, Espı'n JC (2001) Phenolic compounds and related enzymes as determinants of quality in fruits and vegetables. J Sci Food Agric 81:853-876 